\title{
Efficacy of Lamellar Keratoplasty with Acellular Porcine Corneal Stroma in Treatment for Infectious Central and Peripheral Corneal Ulcers
}

\author{
Yingxin Chen \\ Linlin Zhang \\ Zhiling Liu \\ Qiming Liu \\ Minghong Gao (ID)
}

Department of Ophthalmology, General Hospital of Northern Theater Command, Shenyang, People's Republic of China
Correspondence: Minghong Gao Department of Ophthalmology, General Hospital of Northern Theater Command, 83 Wenhua Road, Shenhe District, Shenyang, I I0840, People's Republic of China

Tel +86-133-5245-9433

Email gaominghong88@yeah.net
Background: The aim of this study was to investigate the efficacy of acellular porcine corneal stroma (APCS) transplantation in the treatment of infectious central and peripheral corneal ulcers.

Methods: A total of 45 patients with infectious corneal ulcers who had undergone lamellar keratoplasty using APCS grafts were included. Among these, 24 had lesions located near the pupil (infectious central corneal ulcer group) and 21 had lesions located in the limbus or around the cornea (infectious peripheral corneal ulcer group). Efficacy was assessed in terms of best-corrected visual acuity, graft transparency, corneal neovascularization, corneal reepithelialization, survival rate, and postoperative complications.

Results: Baseline characteristics showed that poor visual acuity and larger-diameter APCS graft in the infectious central corneal ulcer group were comparable with the infectious peripheral corneal ulcer grouper group $(P<0.05)$. After lamellar keratoplasty using APCS grafts, no obvious differences were observed in aspects of graft transparency, corneal neovascularization, or survival rate $(P>0.05)$. Postoperative complications, ie, delayed corneal epithelial healing, rejection episode, recurrence of infection, and graft melting, were not significantly different between the two groups $(P>0.05)$. Visual acuity in bothgroups had improved significantly at 3 months and 6 months postoperation, respectively.

Conclusion: APCS transplantation is safe and efficacious for treating infectious central and peripheral corneal ulcers. Despite its good efficacy, APCS-graft size, implant position, patient indications, and postoperative management should be kept in mind in treatment for infectious corneal ulcers in different locations.

Keywords: acellular porcine corneal stroma, lamellar keratoplasty, infectious central corneal ulcers, infectious peripheral corneal ulcers

\section{Introduction}

Corneal disease has become the leading cause of blindness worldwide. ${ }^{1}$ In a recent estimate, infectious keratitis is the main cause of corneal blindness in China, which is mainly caused by diverse pathogens, including fungi, viruses, bacteria, and Acanthamoeba. ${ }^{2}$ Nowadays, traditional medical therapy is the main approach for keratitis infection; however, therapeutic keratoplasty (KP) is used for patients with severe and progressive infection. ${ }^{3}$ Overall, most corneal ulcers require surgery. ${ }^{4}$ Advances have been obtained in the techniques of therapeutic KP, including penetrating KP (PKP) and lamellar KP (LKP). ${ }^{5,6}$ LKP can improve visual acuity (VA) and reduce intraocular complications better than traditional PKP. ${ }^{7}$ LKP can 
shorten the disease course and effectively control the infection when the cornea has not been perforated and infected lesions have not involved the entire cornea. ${ }^{8,9}$ However, a lack of cornea donors is limiting factor in treating infectious corneal ulcers.

Acellular porcine corneal stromata (APCS), a promising alternative to donor corneas has been approved by China Food and Drug Administration, and has a wide variety of sources, good biocompatibility, and low immunogenicity. ${ }^{10,11}$ Recently, its efficacy has been demonstrated in clinical studies and animal models. For instance, studies have reported that APCS grafts can survive for a long time and VA of patients with infectious keratitis is greatly improved. ${ }^{12,13}$ Another study has reported that APCS transplantation is a safe and effective treatment for fungal corneal ulcers. ${ }^{14} \mathrm{Li}$ et $\mathrm{al}^{5}$ pointed out risk factors affecting the success rate of APCS grafts in infectious keratitis, including infectious pathogens, severity of corneal infection, and size of the graft. In terms of infectious corneal ulcers, poor visual outcomes are closely associated with size and location of ulcers. ${ }^{15}$ At the time of writing, comparison of efficacy of LKP using APCS for treatment of corneal infectious ulcers in different locations has not yet been reported.

Central corneal ulcers are ulcerous lesions located in the center of the cornea thatmainly involve the pupil area, but not the limbus, cover the visual axis, and irreversibly reduce best-corrected VA (BCVA) of the affected eye. ${ }^{16}$ Peripheral corneal ulcers are ulcerous lesion located in the limbus or around the cornea that do not involve the pupil area or only cover the pupil edge and irreversibly reduce BCVA of the affected eye. ${ }^{17}$ The current study aimed compare the efficacy of APCS grafts between infectious central corneal ulcers and infectious peripheral corneal ulcers. Our findings could provide novel insights for treatment of corneal infectious ulcers in different locations.

\section{Methods}

\section{Patients}

We retrospectively analyzed patients with infectious corneal ulcers for whom medication had been ineffective and who were had then been treated with LKP using APCS from January 2016 to January 2020. A total of 45 patients (45 eyes) were analyzed, including 26 men (26 eyes) and 19 women (19 eyes), with an average age of $(58.4 \pm 8.5)$ years. Among them, 24 patients had lesions in the center of the cornea and 21 lesions in the limbus or around the cornea, defined as the infectious central corneal ulcer group $(n=24)$ and the infectious peripheral corneal ulcer group $(n=21)$, respectively. All patients were treated with APCS grafts (AiNear Corneal Engineering, Shenzhen, China), and informed-consent forms were signed.

Inclusion criteria were infectious keratitis that had worsened or persisted after drug treatment for $>2$ weeks, with lesions not involving the posterior elastic layer, age 18-90 years, had cooperated with ophthalmological examinations, treated with APCS grafts, agreed and signed an informed-consent form, and had cooperated with treatment and follow-up. Exclusion criteria were lesion exceeding the limbus, lesion diameter $>8 \mathrm{~mm}$, lesion depth exceeding two-thirds of corneal thickness, corneal perforation, more neovascularization in the cornea, corneal sensation severely decreased, neuroparalytic corneal ulcers, insufficient eyelid closure, severe dry eye, immune corneal disease, whole-body collagen connective-tissue disease, severe allergic constitution, pregnant or lactating, childbirth plans, severe heart and cerebrovascular conditions, very poor general condition, and unsuitable for clinical research.

\section{Surgical Technique}

Before the operation, eyelashes were cut, lacrimal ducts and conjunctival sac flushed, and intraocular pressure reduced. Pilocarpine nitrate eyedrops were applied 30 minutes prior to surgery. After routine disinfection and $2 \%$ lidocaine anesthesia, the eyeball was softened for $10 \mathrm{~min}$ utes and open-eyelid surgery performed. The recipient bed was prepared by trephination using a trephine of appropriate diameter according to the location and size of the lesion. In general, a larger-diameter trephine was selected when lesions were located in the near pupil and a smallerdiameter trephine used when lesions were located in the limbus or around the cornea. A scalpel was used to cut the ulcer tissue layer by layer until the lesion had been completely removed, and then the recipient bed was washed using antifungal (fluconazole injection) or antibacterial (vancomycin injection) drugs. Anterior-chamber irrigation was performed in cases of anterior-chamber empyema. The excised ulcer tissue was sent for microorganism identification. APCS grafts were rehydrated for 1-2 minutes until soft and placed on the recipient bed. Finally, 10-0 nylon sutures were used to suture, starting from the 12 o'clock position, until suture depth was about $80 \%$ of corneal thickness. Tobramycin and dexamethasone ointment were applied into the conjunctival sac of the surgical 
eye and a bandage applied. All operations had been performed by the same experienced surgeon.

\section{Postoperative Management}

All patients were given rational drugs to prevent recurrence of primary disease based on their individual condition. For fungal corneal ulcers, voriconazole was injected into systemic body twice a day for 7-10 days after the operation, and then voriconazole was taken orally twice per day until 1 month after discharge (reexamination of liver and kidney function). Topical treatment with natamycin eyedrops $(0.02 \%)$ was frequently instilled for 3 days, and epithelialization was detected by fluorescent staining. Once reepithelialization was complete, frequency of natamycin eyedrops application was changed to six times a day. For patients with viral corneal ulcers, foscarnet sodium and sodium chloride were infused into the systemic body for 3 days (twice a day), followed by switching to oral famciclovir tablets (three times day) until 1 month after discharge. Topical usage of ganciclovir and recombinant human IFN $\alpha_{2 b}$ eye drops was prescribed (three times a day). For bacterial corneal ulcers, sensitive antibiotic eyedrops (six times a day) and antibiotic eye ointment (once a night) were utilized based on drug-sensitivity tests or experience after surgery. When the patient's condition was stable, they were discharged from hospital. Sutures were removed at postoperative 6-12 months approximately.

\section{Postoperative Evaluation Index}

All patients were followed up for 12 months after surgery. The extent of APCS transparency and neovascularization were calculated. In terms of APCS transparency, the scores were graded from 0 to 5 , as previously described. ${ }^{18,19}$ Briefly, these scores indicated transparency, turbidity limited to shallow layer, mild turbidity of matrix and visible iris and pupil, worsening turbidity but visible pupil, worsening turbidity and just-visible anterior chamber, and invisible anterior chamber, respectively. Neovascularization was graded 0 if there were none, 1-3 if neovascularization had grown into the corneal limbus, the border of APCS, and into APCS, respectively. ${ }^{14}$ Corneal graft failure was defined as irreversible corneal edema after loss of graft clarity. ${ }^{20} \mathrm{BCVA}$ was converted to logarithm of minimal angle of resolution (logMAR) VA to evaluate postoperative recovery. Additionally, rejection episodes, recurrence of infection, and epithelialization were recorded. If epithelialization
Table I Baseline characteristics

\begin{tabular}{|c|c|c|c|}
\hline & $\begin{array}{l}\text { Infectious } \\
\text { central } \\
\text { corneal ulcer } \\
\text { group }(n=24)\end{array}$ & $\begin{array}{l}\text { Infectious } \\
\text { peripheral } \\
\text { corneal ulcer } \\
\text { group }(n=21)\end{array}$ & $P$ \\
\hline Age (years) & $58.4 \pm 8.6$ & $58.3 \pm 8.7$ & 0.960 \\
\hline Sex (male/female) & $12 / 12$ & $14 / 7$ & 0.366 \\
\hline Etiology (n) & & & 0.542 \\
\hline Fungus & 18 & 13 & - \\
\hline Virus & 2 & 4 & - \\
\hline Bacteria & 4 & 3 & - \\
\hline Mixed infection & 0 & I & - \\
\hline $\begin{array}{l}\text { Preoperative } \\
\text { complications (n) }\end{array}$ & & & $>0.999$ \\
\hline Glaucoma & I & I & - \\
\hline BCVA & $2.36 \pm 1.23$ & $1.53 \pm 1.06$ & 0.019 \\
\hline Graft diameter & $7.32 \pm 0.84$ & $4.64 \pm 0.79$ & $<0.0001$ \\
\hline
\end{tabular}

Abbreviation: BCVA, best-corrected visual acuity.

were not complete within 7 days, it was judged to be delayed corneal epithelial healing. ${ }^{21}$

\section{Statistical Analysis}

Data were analyzed using SPSS 17.0. Numerical data were analyzed with Fisher's exact test $(\mathrm{n}<5)$ and $\chi^{2}$ test $(\mathrm{n}>5)$. Age and graft diameter between groups were compared with Student's $t$-test. Significance in BCVA was tested with two-way ANOVA followed by Bonferroni test. $P<0.05$ was deemed statistically significant.

\section{Results}

\section{General Characteristics}

As shown in Table 1, there were no obvious significances in ages, sex, etiology, and preoperative complications between the groups $(P>0.05)$. However, BCVA and diameters of APCS grafts in the infectious central corneal ulcer group did obviously differ from the infectious peripheral corneal ulcer group $(P<0.05)$.

\section{Postoperative Visual Acuity}

As shown in Table 2, BCVA was not significantly different between the groups $(F=3.22, \quad P=0.082)$, though a significant time effect was found $(F=62.71, P<0.0001)$. There was also a significant interaction between time and group ( $F=6.59, P=0.0013$ ). Regarding within-group differences, BCVA in infectious central corneal ulcers had decreased significantly at postoperative 3 months and 
Table 2 Comparison of BCVA at different times

\begin{tabular}{|l|l|l|}
\hline & Infectious central corneal ulcer group $(\mathbf{n = 2 4})$ & Infectious peripheral corneal ulcer group (n=2 I) \\
\hline Preoperative & $2.36 \pm 1.23$ & $1.53 \pm 1.06$ \\
\hline Postoperative 7 days & $2.52 \pm 0.78$ & $1.70 \pm 0.80$ \\
\hline Postoperative I month & $1.63 \pm 0.83$ & $1.19 \pm 0.71$ \\
\hline Postoperative 3 months & $1.53 \pm 0.78^{*}$ & $0.99 \pm 0.64$ \\
\hline Postoperative 6 months & $1.19 \pm 0.75^{*}$ & $0.79 \pm 0.61^{*}$ \\
\hline Postoperative I2 months & $0.61 \pm 0.21^{*}$ & $0.76 \pm 0.57^{*}$ \\
\hline
\end{tabular}

Note: $* P<0.05$, within-groups difference vs preoperative.

remained stable at postoperative 6 and 12 months, indicating VAhad improved at 3 months after surgery and tended to be stable VAin infectious peripheral corneal ulcers had improved at postoperative 6 months and remained stable at 12-month follow-up. These results suggested that VA in the infectious central corneal ulcer grouphad improved more quickly.

\section{Postoperative Complications}

During follow-up, complications, including delayed corneal epithelial healing, rejection, recurrence of infection, and graft melting were not statistically different between the groups $(P>0.05$, Table 3$)$. Interlaminar effusion and hemorrhage and posterior elastic membrane perforation were not found either. Specifically, complete healing of corneal epithelia was achieved in 31 patients within 7 days (Figure 1). Among the 14 patients with delayed corneal epithelial healing, eight were in the infectious central corneal ulcer group and six in the infectious peripheral corneal ulcer group.

In cases of rejection, the earliest one occurred in the infectious peripheral corneal ulcer group, and the latest was 3 months after surgery. In the infectious central corneal ulcer group, six had rejections. Among these, two were well controlled after intensive antirejection therapy, but antirejection reactions in two cases had not reduced by 1 year, indicating failed transplantation. Two cases with rejection were treated with PKP, which achieved good outcomes (Figure 2). There were eight cases of rejection in the infectious peripheral corneal ulcer group, of which one had restored APCS transparency after treatment with antirejection drugs, while two had improved, but the APCS grafts were not transparent. The remaining five cases were treated with PKP (Figure 2).

Four cases of infection recurrence were observed, all in the infectious central corneal ulcer group. Three were fungal keratitis and one viral keratitis. Graft melting is a serious complication of corneal transplantation, and reasons include infectious and uninfectious inflammatory reactions. In the current study, 12 of 45 patients had graft melting, accounting for $26.7 \%$. There were six cases in the infectious central corneal ulcer group, of which two were under control after treatment, but had irreversible turbidity (Figure 3A and B), and six in the infectious peripheral corneal ulcer group, of which two were controlled after treatment with prednisolone acetate eye drops (six times a day), tacrolimus eyedrops (three times a day), deproteinized calf blood-extract eye gel (three times a day), natamycin eye drops (twice a day), tobramycin-dexamethasone ointment (once a night), and sodium hyaluronate eyedrops (four times a day).All had different degrees of grafts thinning (Figure 3C and D). Briefly, four cases of graft melting were caused by neovascularization and rejection episodes and two by infection recurrence in the

Table 3 Comparison of complications between the two groups

\begin{tabular}{|l|l|l|l|}
\hline & $\begin{array}{l}\text { Infectious central corneal ulcer group } \\
(\mathbf{n = 2 4 )}\end{array}$ & $\begin{array}{l}\text { Infectious peripheral corneal ulcer group } \\
(\mathbf{n = 2})\end{array}$ & $P$ \\
\hline Delayed corneal epithelial healing (n) & 8 & 6 & 0.731 \\
\hline Infection episodes (n) & 6 & 8 & 0.344 \\
\hline Recurrence of infection (n) & 4 & 0 & 0.111 \\
\hline Graft melting (n) & 6 & 6 & 0.787 \\
\hline
\end{tabular}



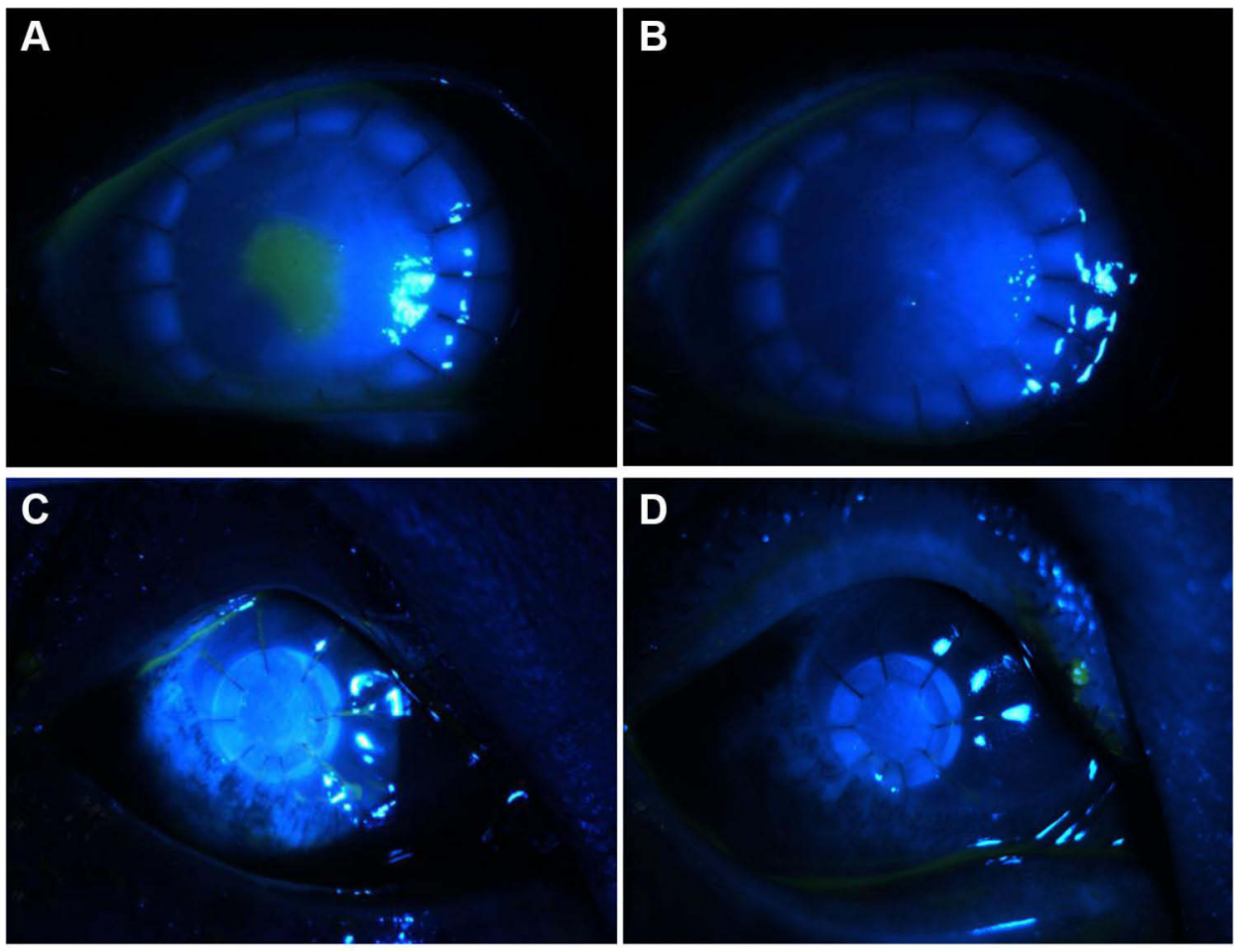

Figure I Images of complete healing of corneal epithelia. (A, B) Epithelial healing at 3 and 7 days after surgery in infectious central corneal ulcers; (C, D)epithelial healing at 3 and 7 days after surgery in infectious peripheral corneal ulcers.
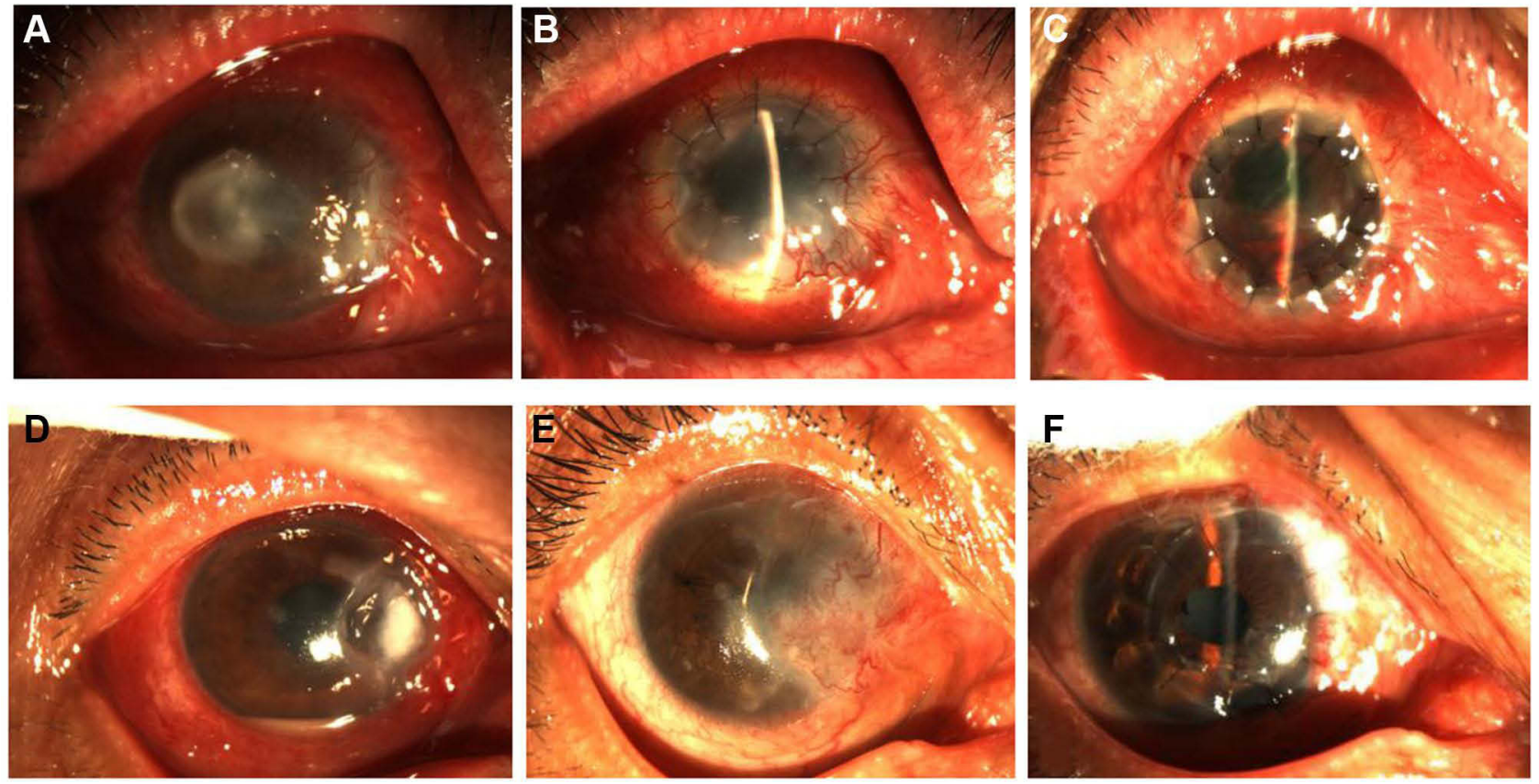

Figure 2 Cases of graft failure. (A-C) Cornea status at preoperation, rejection episode 3 months after APCS transplantation, and after treatment with PKP in infectious central corneal ulcer group. (D-F) Cornea status prior to surgery, at 3 months after APCS transplantation, and after treatment with PKP in infectious peripheral corneal ulcers. APCS, acellular porcine corneal stroma; PKP, penetrating keratoplasty. 

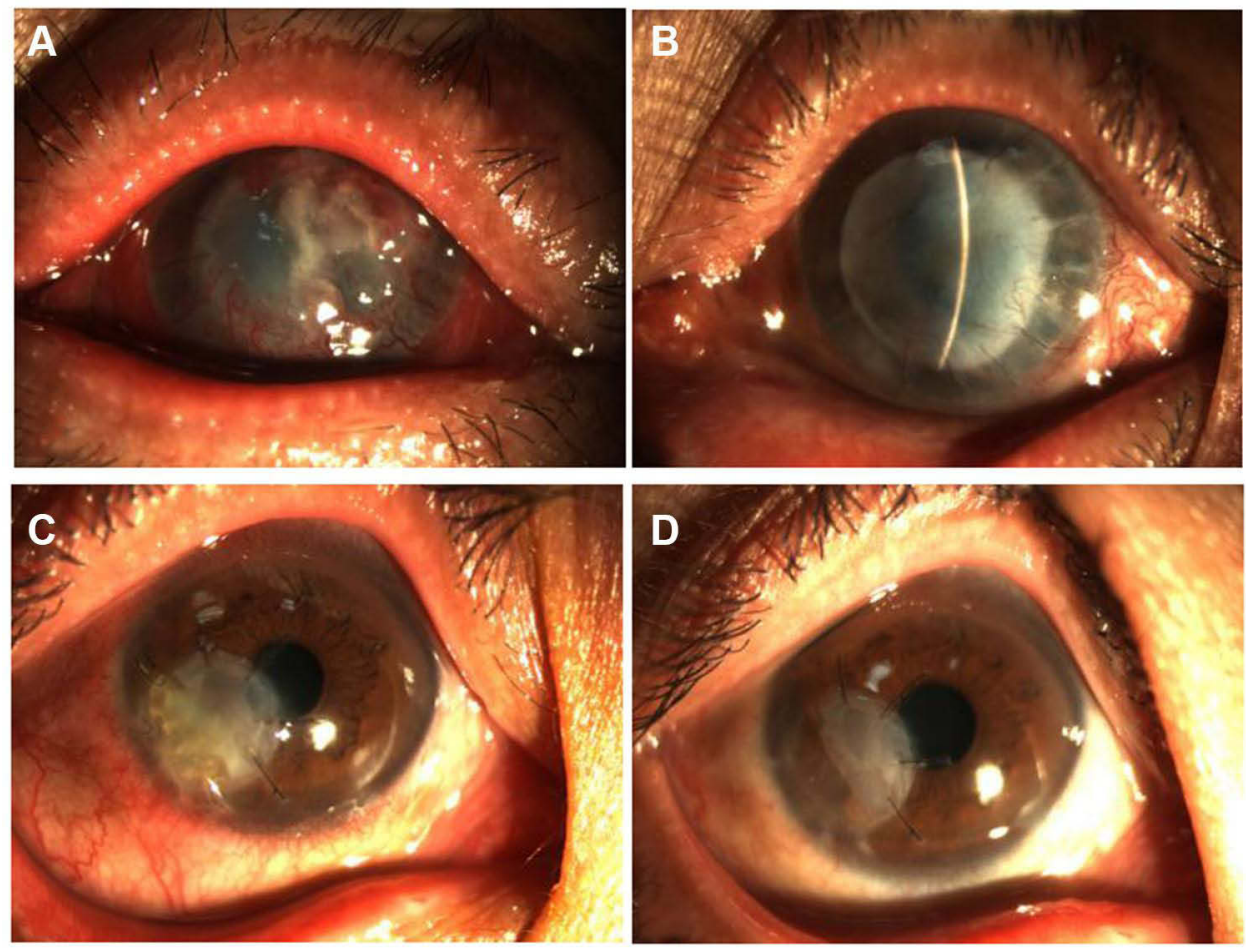

Figure 3 Representative images of graft melting. (A) At 4 months, the APCS graft had dissolved, and irreversible turbidity appeared after therapy (B) in the infectious central corneal ulcer grouper group. (C) At 3 months, the APCS graft had dissolved, and was then controlled after therapy (D) in the infectious peripheral corneal ulcer group.

infectious central corneal ulcer group. In the infectious peripheral corneal ulcer group, six were caused by epithelial exfoliation of grafts and neovascularization. Overall, $83.3 \%$ of graft melting was due to uninfectious factors.

\section{Graft Transparency and Corneal Neovascularization}

During the 12 months of follow-up, seven patients presented graft failure in the infectious central corneal ulcer group and four in the infectious peripheral corneal ulcer group. Among 17 cases in the infectious central corneal ulcer group, corneal transparency was significantly improved. In the infectious peripheral corneal ulcer group, two were graded 0 , eleven graded 1, and were graded 2 (Table 4).

As shown in Table 5,there was no neovascularization of infectious central corneal ulcer groupin 14 cases (58\%) and nine $(43 \%)$ in the infectious peripheral corneal ulcer group. There were no obvious differences between the two groups $(P>0.05)$.

\section{Graft-Survival Rate}

At the last follow-up, 17 APCS grafts in the infectious central corneal ulcer group and 17 in the infectious peripheral corneal ulcer group had survived well (Figure 4, Figure 5, Figure 6, Figure 7, Figure 8). Success rates of corneal transplantation were $71 \%$ and $81 \%$, respectively $(P>0.05$, Figures 5-8).

\section{Discussion}

APCS has recently been deemed a promising material to alleviate the global shortage of corneas; however, challenges frequently occur, including graft rejection or failure. ${ }^{22}$ Although the efficacy of APCS application for infectious corneal ulcers has been reported, ${ }^{14}$ its effects require further investigation. The current study showed that LKP using APCS is an effective and safe treatment for infectious corneal ulcers. In the absence of serious complications, the APCS grafts became transparent and VA significantly improved. No statistical difference was observed between the infectious central and infectious peripheral corneal ulcer groups for survival rate of the grafts, graft transparency, corneal neovascularization, or postoperative complications.

It is well known that VA is closely related to the size and location of ulcers. ${ }^{15}$ In the current study, preoperative BCVA in the infectious central corneal ulcer group was 
Table 4 Graft-transparency scores at postoperative 12 months

\begin{tabular}{|l|l|l|l|}
\hline & $\begin{array}{l}\text { Infectious central corneal ulcer group } \\
(\mathbf{n = 2 4 )}\end{array}$ & $\begin{array}{l}\text { Infectious peripheral corneal ulcer group } \\
(\mathbf{n = 2 1 )}\end{array}$ & $\boldsymbol{P}$ \\
\hline $0, \mathrm{n}(\%)$ & $5(21 \%)$ & $2(10 \%)$ & - \\
\hline $\mathrm{I}, \mathrm{n}(\%)$ & $8(33 \%)$ & $11(52 \%)$ & - \\
\hline $2, \mathrm{n}(\%)$ & $4(17 \%)$ & $4(19 \%)$ & - \\
\hline $3, \mathrm{n}(\%)$ & 0 & 0 & - \\
\hline $4, \mathrm{n}(\%)$ & 0 & 0 & - \\
\hline $5, \mathrm{n}(\%)$ & 0 & 0 & - \\
\hline Miss, $\mathrm{n}(\%)$ & $7(29 \%)$ & $4(19 \%)$ & \\
\hline Total, $\mathrm{n}(\%)$ & $24(100 \%)$ & $21(100 \%)$ & 0.524 \\
\hline
\end{tabular}

Table 5 Neovascularization scores at postoperative 12 months

\begin{tabular}{|l|l|l|l|}
\hline & $\begin{array}{l}\text { Infectious central corneal ulcer group } \\
(\mathbf{n = 2 4})\end{array}$ & $\begin{array}{l}\text { Infectious peripheral corneal ulcer group } \\
(\mathbf{n = 2 1})\end{array}$ & $\boldsymbol{P}$ \\
\hline $0, \mathrm{n}(\%)$ & $14(58 \%)$ & $9(43 \%)$ & - \\
\hline $\mathrm{I}, \mathrm{n}(\%)$ & $2(9 \%)$ & $3(14 \%)$ & - \\
\hline $2, \mathrm{n}(\%)$ & $\mathrm{I}(4 \%)$ & $3(14 \%)$ & - \\
\hline $3, \mathrm{n}(\%)$ & 0 & $2(10 \%)$ & - \\
\hline Miss, $\mathrm{n}(\%)$ & $7(29 \%)$ & $4(19 \%)$ & \\
\hline Total, $\mathrm{n}(\%)$ & $24(100 \%)$ & $21(100 \%)$ & 0.290 \\
\hline
\end{tabular}

higher than that of the infectious peripheral corneal ulcer group, indicating poor VA. After surgery, VA had significantly improved and then tended to stablize in the two groups. Previous research has demonstrated that APCS grafts gradually (rather than immediately) recover transparency after operation, different from human corneal transplants. ${ }^{23}$ Correspondingly, VA was noted to increase gradually over time as well, consistent with our results. A possible reason is that the alignment of collagen fibrils is inevitably slightly disrupted after porcine corneas have been treated with decellularization, as shown in a previous study. ${ }^{24}$ Changes in in collagen-fibril arrangement may affect light transmission, thereby leading to cloudy grafts. ${ }^{25}$ Additionally, evidence have indicated that grafts size is closely associated with the success rate of transplantation. For instance, Williams et $\mathrm{al}^{26}$ and $\mathrm{Li}$ et $\mathrm{al}^{5}$ showed that graft size $>8 \mathrm{~mm}$ haad a higher transplantation-failure rate. In our study, the size of APCS grafts in the infectious central corneal ulcer group was 6-9.25 $\mathrm{mm}$ (five cases $\geq 8 \mathrm{~mm}$ ), with a $71 \%$ transplantation-success rate, and that of the infectious peripheral corneal ulcer group was 3-6 mm, with an $81 \%$ transplantation-success rate. There was no statistically significant difference between the two groups. We speculated that this result was mainly due to the small number of patients having received APCS grafts of diameter $\geq 8 \mathrm{~mm}$ in the infectious central corneal ulcer group. In addition, some ulcers in the infectious peripheral corneal ulcer group were located in the limbus or around the cornea, which are closely associated with immunorejection, thereby affecting the survival of implants, as shown in a previous study. ${ }^{27}$ Overall, APCS transplantation is an effective and safe treatment for infectious corneal ulcers. Additionally, we suggest that larger grafts are selected to cover the visual axis, but not to exceed $8 \mathrm{~mm}$ in infectious central corneal ulcers. For patients with infectious peripheral corneal ulcers, smaller grafts should be selected, but avoiding the corneal limbus.

Corneal reepithelialization is an important indicator after operation. At 2 months after transplantation, 


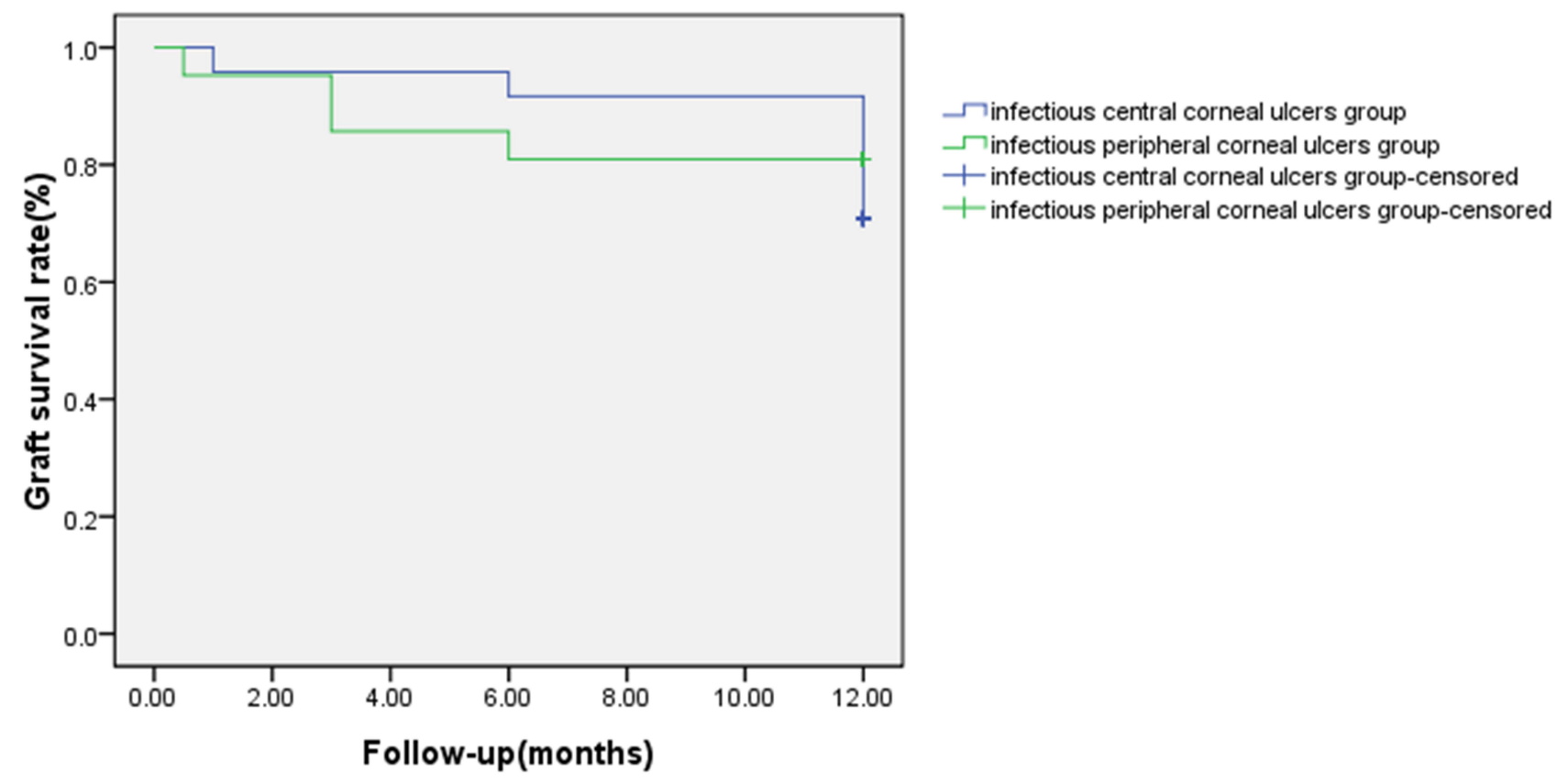

Figure 4 Graft-survival rates in the two groups.
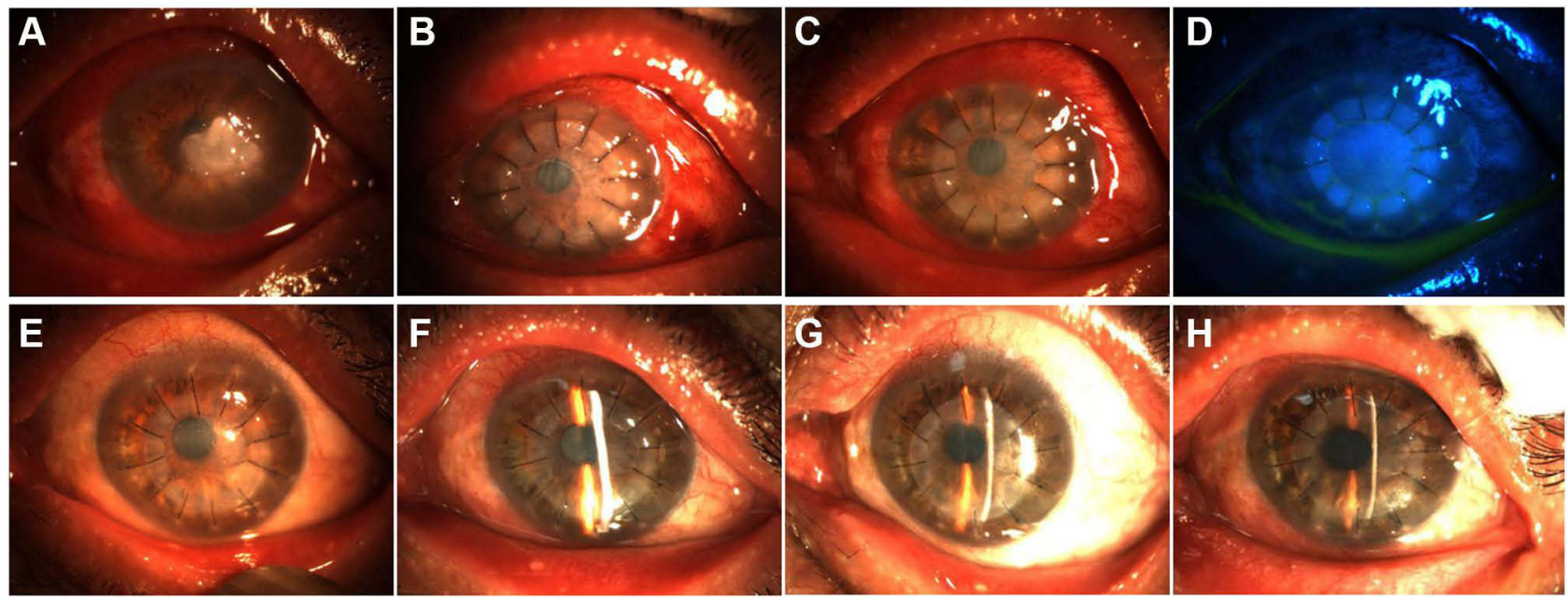

Figure 5 Successful graft transplantation in the infectious central corneal ulcer group. (A-D) Before surgery (A) and at I day (B), 7 days (C and, D), I month (E), 3 months (F), 6 months (G), and 12 months $(\mathbf{H})$ postoperatively.

complete reepithelialization and stromal-cell ingrowth without inflammatory-cell infiltration and neovascularization were observed in a previous study. ${ }^{28}$ Our study showed that corneal reepithelialization had completed in most patients within 7 days. Of these, delayed corneal epithelial healing occurred in 14 cases, which accounted for $31 \%$. The percentage was higher than previous study that reported reepithelialization had completed within 1 week in all patients. ${ }^{29}$ Reasons may be related to ocular surface condition, age, and ulcer location. Specifically, most patients in our study had symptoms of dry and astringent eyes before surgery. Due to damaged ocular surfaces, reepithelialization was influenced, conformed with a previous study. ${ }^{30}$ Additionally, Sun et $\mathrm{al}^{31}$ revealed that age is a relevant factor influencingreepithelialization. Surprisingly, there were eight cases of delayed corneal epithelial healing in the infectious central corneal ulcer group, of whom five were aged $>60$ years. Last but not least, a previous study showed that delayed healing of epithelium is associated with lesions located in the 

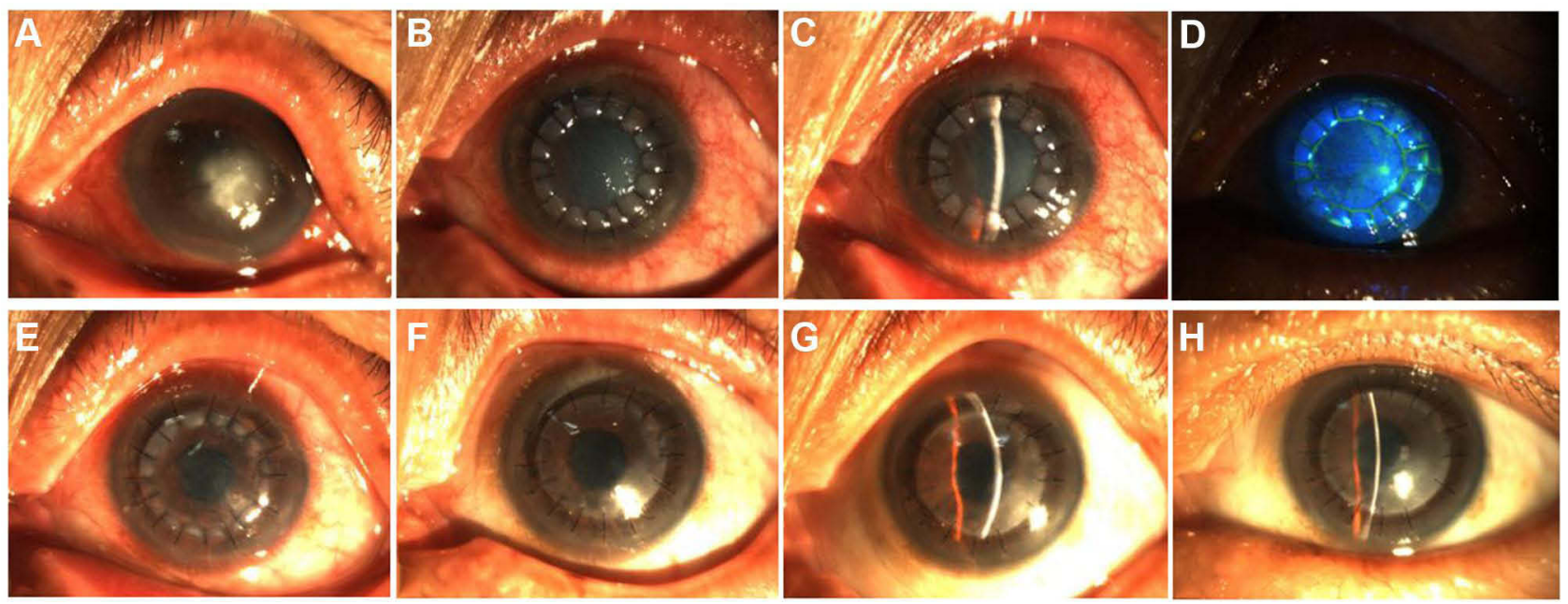

Figure 6 Another successful graft transplantation in the infectious central corneal ulcer group. (A-D) Before surgery (A) and at I day (B), 7 days (C and, D), I month (E), 3 months $(\mathbf{F}), 6$ months $(\mathbf{G})$, and 12 months $(\mathbf{H})$ postoperatively.
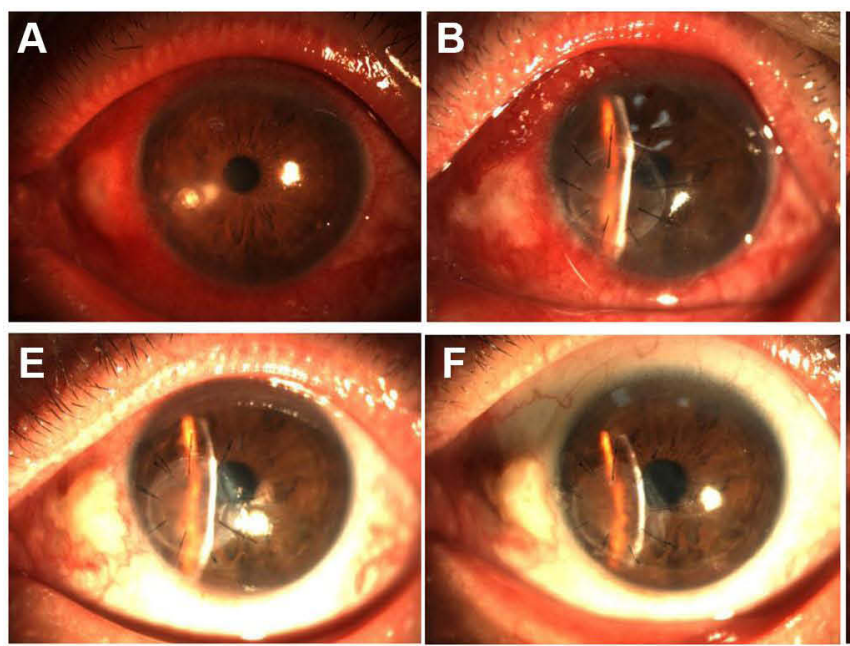
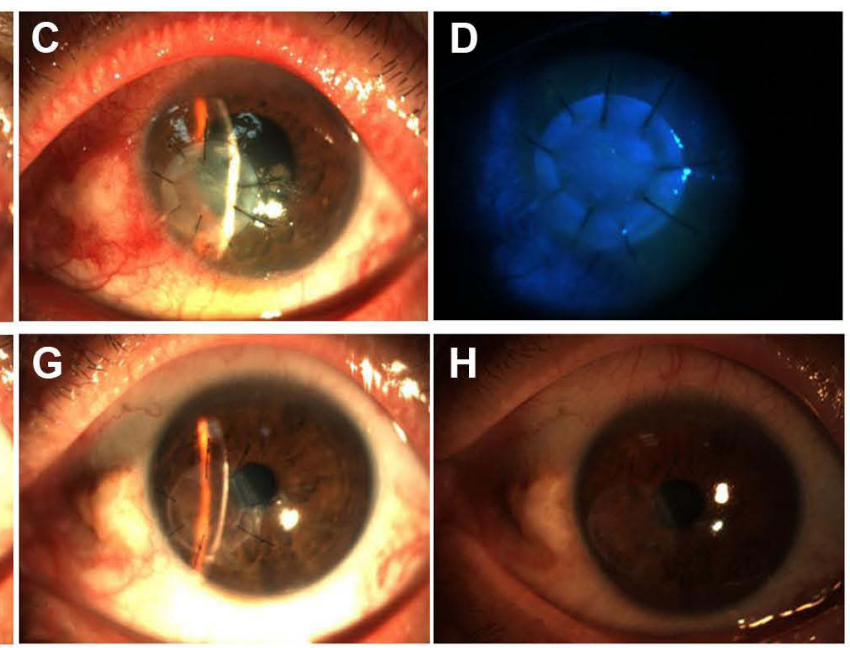

Figure 7 Successful graft transplantation in the infectious peripheral corneal ulcer group. (A-D) Before surgery (A) and at I day (B), 7 days (C and, D), I month (E), 3 months $(\mathbf{F}), 6$ months $(\mathbf{G})$, and 12 months $(\mathbf{H})$ postoperatively.

corneal limbus. ${ }^{32}$ Therefore, it is necessary to actively promote reepithelialization for older patients, poor ocular surface condition, and lesions involving the limbus, in order to improve the survival rate of APCS grafts.

Antirejection therapy plays key role in the success of corneal transplantations. In high-risk corneas, rejection episodes and failure rates are significantly increased. ${ }^{33}$ In addition, rejection rates in larger grafts $(9 \mathrm{~mm})$ are not obviously different compared with conventionally sized grafts; ${ }^{34}$ however, there has been no comparison with smaller grafts. In the current study, rejection rates in the infectious central corneal ulcer $(6-9.25 \mathrm{~mm})$ and infectious peripheral corneal ulcer (3-6 mm) groups were $25 \%$ and $38 \%$, respectively, and the difference was not statistically significant. Reversal of rejection was achieved in $35.7 \%$ (five of 14) of cases of our study, comparable to previous studies. ${ }^{35,36}$ Additionally, some patients were switched to PKP treatment after graft failure due to rejection in our study, mainly due to the following factors. First, patient conditions were progressively aggravated after treatment with antirejection drugs for 3 months, including continuous edema and turbidity around the graft and extensive graft neovascularization. Second, previous studies have demonstrated that PKP achieveds good therapeutic effects in patients with graft failure after being treated with 

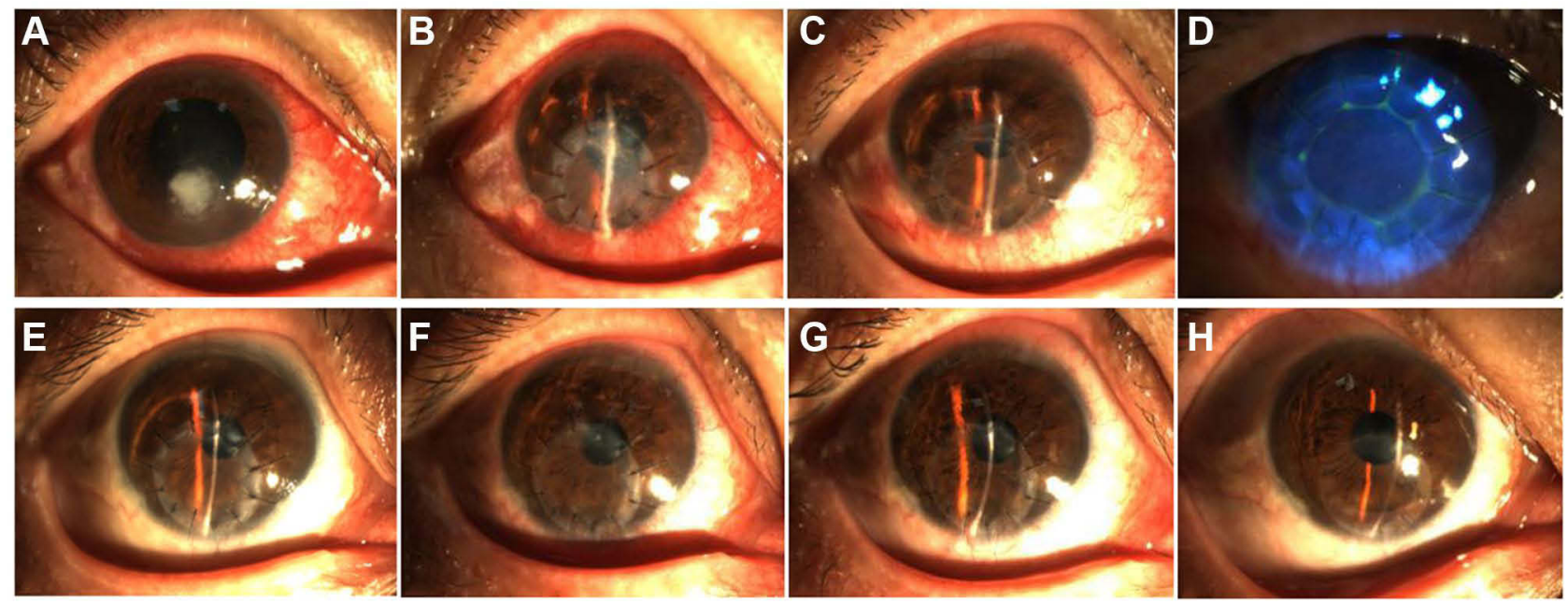

Figure 8 Another successful graft transplantation in the infectious peripheral corneal ulcer group. (A-D) Before surgery (A) and at I day (B), 7 days (C and, D), I month (E), 3 months (F), 6 months $(\mathbf{G})$, and 12 months $(\mathbf{H})$ postoperatively.

deep anterior LKP using APCS. ${ }^{5,37}$ Last, in consideration of old patients and long course of disease, PKP was used. Those findings suggest that antirejection treatment should be routinely conducted after APCS transplantation, but the duration of antirejection treatment needs to be investigated.

Research has revealed the high risk of recurrence of infection based on etiology and graft size. ${ }^{38}$ Recurrence rates were nearly threefold higher in fungal keratitis than bacterial keratitis, and graft size was deemed as independent risk factor. A similar study also reported that larger grafts were closely associated with higher risk of infection recurrence. ${ }^{39}$ In our study, four of 45 cases had recurrent infections, all in the infectious central corneal ulcer group and with larger APCS grafts. Among these, three had fungal keratitis (75\%). Moreover, uninfectious graft melting was a common cause of graft failure in the current study, consistent with previous reseach. ${ }^{5}$ Graft melting is a devastating complication, and it is mainly caused by neovascularization, rejection episodes, and persistent corneal epithelial defects. ${ }^{40}$ Overall, reduction in ocular surface inflammation and inhibition of neovascularization are particularly important for KP success.

There were some limitations in the current study. First, we had a short follow-up and small sample. Second, evaluations of changes in corneal thickness, growth of corneal nerves, and time of thread loosening were not conducted. In future, we will conduct a large randomized controlled study and then evaluate corneal changes to verify the efficacy of APCS transplantation for infectious corneal ulcers.

\section{Conclusion}

APCS transplantation is safe and efficacious in treating infectious central corneal ulcers and infectious peripheral corneal ulcers. Despite good efficacy, the size of APCS grafts, implant location, patient indications, and postoperative management should be kept in mind in the treatment of infectious corneal ulcers in different locations.

\section{Abbreviations}

APCS, acellular porcine corneal stroma; BCVA, bestcorrected visual acuity; PKP, penetrating keratoplasty; LKP, lamellar keratoplasty; logMAR, logarithm of minimal angle of resolution.

\section{Data Sharing Statement}

All data generated or analyzed in the study are included in this article.

\section{Ethical Approval and Informed Consent}

This study was approved by the Ethics Committee of the General Hospital of Northern Theater Command (K [2018] 05), and was conducted in accordance with the Declaration of Helsinki. Informed consent was obtained from each patient.

\section{Consent for Publication}

All patients consent to publish the associated data and accompanying images. 


\section{Author Contributions}

All authors made substantial contributions to conception and design, acquisition of data, or analysis and interpretation of data, took part in drafting the article or revising it critically for important intellectual content, agreed to submit to the current journal, gave final approval to the version to be published, and agree to be accountable for all aspects of the work.

\section{Funding}

The study was funded by the National Health and Family Planning Commission Medical and Health Science and Technology Development Research Center (W2017JM19).

\section{Disclosure}

All authors declare that they have no competing interests.

\section{References}

1. Whitcher JP, Srinivasan M, Upadhyay MP. Corneal blindness: a global perspective. Bull World Health Organ. 2001;79(3):214-221.

2. Cao J, Yang Y, Yang W, et al. Prevalence of infectious keratitis in Central China. BMC Ophthalmol. 2014;14:43. doi:10.1186/14712415-14-43

3. Sharma N, Sachdev R, Jhanji V, Titiyal JS, Vajpayee RB. Therapeutic keratoplasty for microbial keratitis. Curr Opin Ophthalmol. 2010;21 (4):293-300. doi:10.1097/ICU.0b013e32833a8e23

4. Stamate AC, Tătaru CP, Zemba M. Update on surgical management of corneal ulceration and perforation. Rom J Ophthalmol. 2019;63 (2):166-173. doi:10.22336/rjo.2019.25

5. Li S, Li M, Gu L, et al. Risk factors influencing survival of acellular porcine corneal stroma in infectious keratitis: a prospective clinical study. J Transl Med. 2019;17(1):434. doi:10.1186/s12967-01902192-Z

6. Zheng J, Huang X, Zhang Y, et al. Short-term results of acellular porcine corneal stroma keratoplasty for herpes simplex keratitis. Xenotransplantation. 2019;26(4):e12509. doi:10.1111/xen.12509

7. Shi W, Wang T, Xie L, et al. Risk factors, clinical features, and outcomes of recurrent fungal keratitis after corneal transplantation. Ophthalmology. 2010;117(5):890-896. doi:10.1016/j.ophtha.2009.10.004

8. Corneal Disease Group OBoCMA. Expert consensus on keratoplasty in China (2015). Zhonghua Yan Ke Za Zhi. 2015;51(12):888-891.

9. Corneal Disease Group OBoCMA. Consensus of clinical therapists for infectious keratopathy (2011). Zhonghua Yan Ke Za Zhi. 2012;48 (1):72-75.

10. Shi WY, Xie LX. [Focus on the clinical application of the first artificial bioengineered cornea in China]. Zhonghua Yan Ke Za Zhi 2016;52(3):161-163. doi:10.3760/cma.j.issn.0412-4081.2016.03.001

11. Wong ML, Wong JL, Vapniarsky N, Griffiths LG. In vivo xenogeneic scaffold fate is determined by residual antigenicity and extracellular matrix preservation. Biomaterials. 2016;92:1-12. doi:10.1016/j. biomaterials.2016.03.024

12. Tian BS, Li SQ, Zhang EE, et al. The lived experiences of patients undergoing acellular porcine corneal stroma transplantation. Int J Ophthalmol. 2018;11(10):1716-1720. doi:10.18240/ijo.2018.10.22

13. Pang K, Du L, Wu X. A rabbit anterior cornea replacement derived from acellular porcine cornea matrix, epithelial cells and keratocytes. Biomaterials. 2010;31(28):7257-7265. doi:10.1016/j.biomateria 1s.2010.05.066
14. Zhang MC, Liu X, Jin Y, Jiang DL, Wei XS, Xie HT. Lamellar keratoplasty treatment of fungal corneal ulcers with acellular porcine corneal stroma. Am J Transplant. 2015;15(4):1068-1075. doi:10.1111/ajt.13096

15. Ibrahim YW, Boase DL, Cree IA. Epidemiological characteristics, predisposing factors and microbiological profiles of infectious corneal ulcers: the Portsmouth corneal ulcer study. $\mathrm{Br}$ J Ophthalmol. 2009;93(10):1319-1324. doi:10.1136/ bjo.2008.151167

16. Frueh BE. [Central corneal diseases]. Klin Monbl Augenheilkd. 1999;214(5):291-294. doi:10.1055/s-2008-1034797

17. Shi W, Liu M, Gao H, Li S, Wang T, Xie L. Penetrating keratoplasty with small-diameter and glycerin-cryopreserved grafts for eccentric corneal perforations. Cornea. 2009;28(6):631-637. doi:10.1097/ ICO.0b013e318191b857

18. Li S, Lu H, Zang Y, et al. Clinical efficacy of acellular porcine corneal stroma deep lamellar keratoplasty for infectious corneal ulcer. Ophthalmol CHN. 2018;27(3):164-170.

19. Sugaya S, Chen WS, Cao Z, et al. Comparison of galectin expression signatures in rejected and accepted murine corneal allografts. Cornea. 2015;34(6):675-681. doi:10.1097/ICO.0000000000000439

20. Kosker M, Suri K, Duman F, Hammersmith KM, Nagra PK, Rapuano CJ. Long-term outcomes of penetrating keratoplasty and Descemet stripping endothelial keratoplasty for Fuchs endothelial dystrophy: fellow eye comparison. Cornea. 2013;32(8):1083-1088. doi:10.1097/ICO.0b013e31828ea02a

21. Das S, Langenbucher A, Seitz B. Delayed healing of corneal epithelium after phototherapeutic keratectomy for lattice dystrophy. Cornea. 2005;24(3):283-287. doi:10.1097/01. ico.0000138853.26332.55

22. Palchesko RN, Carrasquilla SD, Feinberg AW. Natural biomaterials for corneal tissue engineering, repair, and regeneration. Adv Healthc Mater. 2018;7(16):e1701434. doi:10.1002/adhm.201701434

23. Charidimou A. Cerebral amyloid angiopathy-related transient focal neurological episodes (CAA-TFNEs): a well-defined clinical-radiological syndrome. J Neurol Sci. 2019;406:116496. doi:10.1016/j.jns.2019.116496

24. Yoeruek E, Bayyoud T, Maurus C, et al. Decellularization of porcine corneas and repopulation with human corneal cells for tissue-engineered xenografts. Acta Ophthalmol. 2012;90(2):e125131. doi:10.1111/j.1755-3768.2011.02261.x

25. Maurice DM. The structure and transparency of the cornea. J Physiol. 1957;136(2):263-286. doi:10.1113/jphysiol.1957.sp005758

26. Williams KA, Roder D, Esterman A, Muehlberg SM, Coster DJ. Factors predictive of corneal graft survival. Report from the Australian corneal graft registry. Ophthalmology. 1992;99 (3):403-414. doi:10.1016/S0161-6420(92)31960-8

27. Lin L. Bioengineered keratoplasty for infectious keratitis. Int Eye Sci. 2019;19(10):1728-1732

28. Shao Y, Tang J, Zhou Y, et al. A novel method in preparation of acellularporcine corneal stroma tissue for lamellar keratoplasty. Am $J$ Transl Res. 2015;7(12):2612-2629.

29. Li S, Deng Y, Tian B, et al. Healing characteristics of acellular porcine corneal stroma following therapeutic keratoplasty. Xenotransplantation. 2020;27(2):e12566. doi:10.1111/xen.12566

30. Bourcier T, Acosta MC, Borderie V, et al. Decreased corneal sensitivity in patients with dry eye. Invest Ophthalmol Vis Sci. 2005;46 (7):2341-2345. doi:10.1167/iovs.04-1426

31. Sun X, Shi W, Wang T, Wang S. Factors associated with delayed epithelial healing in early stage after lamellar keratoplasty. J Clin Ophthalmol. 2013;2:97-100.

32. Ti SE, Anderson D, Touhami A, Kim C, Tseng SC. Factors affecting outcome following transplantation of ex vivo expanded limbal epithelium on amniotic membrane for total limbal deficiency in rabbits. Invest Ophthalmol Vis Sci. 2002;43(8):2584-2592. 
33. Qazi Y, Hamrah P. Corneal Allograft Rejection: immunopathogenesis to Therapeutics. J Clin Cell Immunol. 2013;2013(Suppl 9):006. doi:10.4172/2155-9899.S9-006

34. Giannaccare G, Weiss JS, Sapigni L, et al. Immunologic stromal rejection after deep anterior lamellar keratoplasty with grafts of a larger size $(9 \mathrm{~mm})$ for various stromal diseases. Cornea. 2018;37 (8):967-972. doi:10.1097/ICO.0000000000001584

35. Sedghipour MR, Sorkhabi R, Shenasi A, Dehghan H. Outcome of penetrating keratoplasty in corneal ulcer: a single-center experience. Clin Ophthalmol. 2011;5:1265-1268. doi:10.2147/OPTH.S22959

36. Yalniz-Akkaya Z, Burcu A, Doğan E, Onat M, Ornek F. Therapeutic penetrating keratoplasty for infectious and non-infectious corneal ulcers. Int Ophthalmol. 2015;35(2):193-200. doi:10.1007/s10792-014-9931-y
37. Zheng Q, Zhang Y, Ren Y, et al. Deep anterior lamellar keratoplasty with cross-linked acellular porcine corneal stroma to manage fungal keratitis. Xenotransplantation. 2021;28(2):e12655. doi:10.1111/ xen. 12655

38. Chatterjee S, Agrawal D. Recurrence of infection in corneal grafts after therapeutic penetrating keratoplasty for microbial keratitis. Cornea. 2020;39(1):39-44. doi:10.1097/ICO.0000000000002044

39. Mundra J, Dhakal R, Mohamed A, et al. Outcomes of therapeutic penetrating keratoplasty in 198 eyes with fungal keratitis. Indian JOphthalmol. 2019;67(10):1599-1605. doi:10.4103/ijo.IJO_1952_18

40. Zhu BB, Zhou J, Zheng J, et al. Corneal graft melting: a systematic review. Int $J$ Ophthalmol. 2020;13(3):493-502. doi:10.18240/ ijo.2020.03.19

\section{Publish your work in this journal}

Therapeutics and Clinical Risk Management is an international, peerreviewed journal of clinical therapeutics and risk management, focusing on concise rapid reporting of clinical studies in all therapeutic areas, outcomes, safety, and programs for the effective, safe, and sustained use of medicines. This journal is indexed on PubMed Central, CAS,
EMBase, Scopus and the Elsevier Bibliographic databases. The manuscript management system is completely online and includes a very quick and fair peer-review system, which is all easy to use. Visit http://www.dovepress.com/testimonials.php to read real quotes from published authors. 